\title{
GAMBARAN TINGKAT PENGETAHUAN IBU TERHADAP PENYAKIT HIV/AIDS DI PROVINSI BALI
}

\author{
Luh Putu Virra Indah Perdanawati *, Ni Made Anggia Paramesthi Fajar, I Dewa Made Suka
}

Pusat Studi Kependudukan Universitas Ngurah Rai

Email:virraindah30@gmail.com

\begin{abstract}
ABSTRAK
Penularan penyakit HIV/AIDS pada dasarnya dapat di cegah apabila tidak melakukan tindakan-tindakan berisiko. Pengetahuan ibu mengenai penyakit HIV/AIDS hendaknya dapat diketahui sejak dini sehingga sangat bermanfaat bagi perkembangan ibu dan tumbuh kembang anak (Djoerban, 2014). Penelitian ini bertujuan untuk mengetahui tingkat pengetahuan ibu mengenai HIV/AIDS di Provinsi bali. Penelitian yang dilaksanakan bersifat studi deskriptif menggunakan data sekunder Riskesdas Provinsi Bali Tahun 2017. Data yang diperoleh kemudian di analisis secara univariat. Hasil penelitian didapatkan bahwa berdasarkan tingkat pengetahuan responden tentang HIV/AIDS dapat diketahui 32,5\% memiliki tingkat pengetahuan kurang; $62,5 \%$ memiliki tingkat pengetahuan cukup; dan hanya $4,9 \%$ memiliki tingkat pengetahuan baik. Informasi tentang HIV/AIDS yang paling banyak didapatkan masyarakat berasal dari tenaga kesehatan sebesar $64,6 \%$. Selain itu, sebagian besar responden akan merasa malu jika ada anggota keluarganya yang menderita HIV yaitu sebesar $44,6 \%$ dan lebih dari $80 \%$ responden menyatakan setuju bahwa orang lain akan berbicara buruk jika ada yang mengidap HIV. Saran kepada BKKBN Provinsi Bali agar dapat memfasilitasi pelaksanaan penyuluhan HIV/AIDS yang tidak terbatas pada populasi kunci namun juga menjangkau seluruh lapisan masyarakat.
\end{abstract}

Kata Kunci: HIV/AIDS, Pengetahuan, Stigma, Diskriminasi

\begin{abstract}
Basically HIV/AIDS transmitted could be prevented if did not take any risk actions. Mother's knowledge about HIV/AIDS should be known early and that it is very beneficial for the mother and child development (Djoerban, 2014). The purposed of this research was to knowing the level of mother's knowledge about HIV/AIDS in Bali Province. The research conducted was a descriptive study and the data used in this study are secondary data from Riskesdas 2017. The research method was used in this study was univariate analysist. Based on the level of knowledge of respondents about HIV/AIDS that 32,5\% have less knowledge; $62,5 \%$ have a sufficient level of knowledge, and only $4,9 \%$ have a good level of knowledge. The information about HIV/AIDS that was most obtained by the community came from health workers by $64,6 \%$. Besides, most respondents will feel ashamed if there are family members who suffer from HIV, amounting to $44,6 \%$ and more than $80 \%$ of respondents said that they agreed that others would speak worse if someone with HIV around them. Suggestion for BKKBN Bali Province to implemented HIV/AIDS promotion is not only to the key population but also to each levels of community.
\end{abstract}

Keywords: HIV/AIDS, Knowledge, Stigma, Discrimination 


\section{PENDAHULUAN}

Jumlah kasus HIV/AIDS merupakan salah satu masalah kesehatan dunia dimana Indonesia merupakan negara urutan ke-5 paling berisiko HIV/AIDS. Berdasarkan data infodatin tahun 2018, jumlah kasus HIV dari tahun 2015 hingga tahun 2017 selalu meningkat mulai dari 859 kasus HIV tahun 2005 menjadi 48.300 kasus tahun 2017. Berdasarkan sebaran kasusnya, Provinsi Bali menduduki posisi ke-6 provinsi dengan kasus HIV berbanyak di Indonesia (Pusat Data dan Informasi Kemenes RI, 2018).

Intervensi yang dilakukan pemerintah Indonesia dalam rangka menanggulangi kasus HIV/AIDS di Indonesia antara lain bertujuan untuk pencegahan. Pencegahan dilakukan dengan penemuan penderita secara dini yang dilanjutkan dengan konseling (Direktorat Bina Farmasi Klinik dan Komunitas Ditjen Bina Kefarmasian dan Alat Kesehatan, 2006).

Survei di Indonesia melaporkan bahwa penderita HIV/AIDS golongan homoseksual, pengguna narkoba suntik (PENASUN), dan golongan penderita lainnya menolak untuk di lakukan tes HIV, salah satunya disebabkan oleh ketakutan akan diskriminasi oleh masyarakat. Penyakit HIV/AIDS pada dasarnya dapat di cegah atau di hindari penularannya apabila tidak melakukan tindakan-tindakan berisiko seperti seks bebas, menggunakan narkoba suntik secara bergantian dan menerima transfusi darah dari penderita HIV/AIDS (Direktorat Bina Farmasi Klinik dan
Komunitas Ditjen Bina Kefarmasian dan Alat Kesehatan, 2006).

Tes darah merupakan cara untuk dapat mengetahui seseorang terinfeksi HIV atau tidak. Kesadaran seseorang untuk melakukan tes HIV di fasilitas kesehatan untuk menegakkan diagnosis akan memaksimalkan kesempatan ODHA untuk mendapatkan pengobatan. Sehingga akan mengurangi kejadian penyakit terkait HIV dan menurunkan tingkat kematian serta mencegah penularan kepada pasangan seksual atau dari ibu ke bayinya (Kemenkes RI, 2013).

Kesehatan dan pengobatan merupakan salah satu masalah yang paling penting dipertimbangkan untuk meyakinkan bahwa bayi sehat dan terbebas dari penyakit menular dan berbahaya. Oleh karena itu pengetahuan ibu mengenai penyakit HIV/AIDS hendaknya dapat diketahui sejak dini sehingga sangat bermanfaat bagi perkembangan ibu dan tumbuh kembang anak (Djoerban, 2014).

\section{METODE PENELITIAN}

Penelitian yang dilaksanakan bersifat studi deskriptif yaitu suatu penelitian untuk memecahkan masalah yang diselidiki dengan cara mendeskripsikan atau menggambarkan obyek penelitian berdasarkan fakta-fakta yang tampak atau sebagaimana adanya. Data yang digunakan dalam penelitian ini adalah data sekunder Riskesdas Provinsi Bali Tahun 2017. Data yang diperoleh kemudian di analisis secara univariat untuk memperoleh gambaran 
karakteristik responden dan tingkat pengetahuannya terhadap HIV/AIDS.

\section{HASIL}

Berdasarkan tabel 1 dapat diketahui bahwa jumlah responden mencapai 751 orang yang terbagi menjadi 5 kelompok umur dengan umur termuda yaitu 15 tahun dan umur tertua yaitu 49 tahun. Jika dilihat dari proporsinya maka mayoritas responden berumur 45-49 tahun sebesar $16 \%$, sedangkan kelompok umur terendah yaitu 25-29 tahun sebesar 10,7\%. Sebagian besar responden memiliki tingkat pendidikan menengah yaitu $57 \%$ dengan tingkat pendidikan SMP dan 20,9\% dengan tingkat pendidikan SD. Jika dilihat dari karakteristik tempat tinggal maka dapat diketahui sebagian besar yaitu 548 orang $(73 \%)$ tinggal di daerah tergolong daerah urban (perkotaan) dengan tingkat pendapatan yang tergolong sangat sejahtera sebesar $33 \%$.

Tabel 1 Distribusi Frekuensi

Karakteristik Responden

\begin{tabular}{|c|c|c|}
\hline Variabel & $\mathbf{f}$ & $(\%)$ \\
\hline \multicolumn{3}{|l|}{ Umur } \\
\hline 15-19 tahun & 108 & 14,4 \\
\hline 20-24 tahun & 104 & 13,8 \\
\hline 25-29 tahun & 80 & 10,7 \\
\hline 30-34 tahun & 106 & 14,1 \\
\hline 35-39 tahun & 116 & 15,4 \\
\hline 40-44 tahun & 117 & 15,6 \\
\hline 45-49 tahun & 120 & 16,0 \\
\hline \multicolumn{3}{|l|}{ Tingkat Pendidikan } \\
\hline Tidak sekolah & 17 & 2,3 \\
\hline SD & 157 & 20,9 \\
\hline SMP & 428 & 57,0 \\
\hline $\mathrm{SMA} / \mathrm{PT}$ & 149 & 19,8 \\
\hline \multicolumn{3}{|l|}{ Tempat Tinggal } \\
\hline Urban & 548 & 73,0 \\
\hline Rural & 203 & 27,0 \\
\hline \multicolumn{3}{|l|}{ Tingkat Pendapatan } \\
\hline Sangat miskin & 63 & 8,4 \\
\hline miskin & 103 & 13,7 \\
\hline Menengah & 132 & 17,6 \\
\hline Sejahtera & 199 & 26,5 \\
\hline Sangat sejahtera & 254 & 33,8 \\
\hline
\end{tabular}

Berdasarkan tabel 2 dapat diketahui bahwa 94,54\% responden pernah mendengar tentang HIV/AIDS. Lebih dari $50 \%$ responden juga sudah mengetahui bahwa risiko penularan HIV dapat dikurangi dengan berhubungan seks memakai kondom dan tidak bergantiganti pasangan. Pada pernyataan media penularan HIV/AIDS terlihat bahwa dari pernyataan bahwa HIV dapat menular melalui gigitan nyamuk, 53,79\% menjawab "tidak" dan pada pernyataan HIV dapat menular melalui makanan terlihat bahwa 55,39\% responden menjawab "tidak". Selain itu pada item pernyataan HIV dapat ditularkan melalui kehamilan, melahirkan dan menyusui lebih dari $80 \%$ responden menjawab "ya". Namun pada item pernyataan HIV dapat ditularkan melalui cairan saliva $82,42 \%$ menjawab "ya" dan pada item pernyataan HIV dapat ditularkan melalui jarum suntik yang tidak steril $92,81 \%$ menjawab "tidak".

Pada pernyataan tentang risiko orang pengidap HIV/AIDS dapat diketahui bahwa sebagian besar responden yaitu $82,16 \%$ telah mengetahui bahwa seseorang dapat mengidap HIV/AIDS walaupun terlihat sehat. $74,30 \%$ responden menjawab bahwa tidak benar seseorang yang mengidap HIV/AIDS dapat terlihat dari penampilannya dan $100 \%$ responden menjawab bahwa tidak benar seseorang yang mengidap HIV/AIDS dapat terlihat dari perilakunya. Pada item pernyataan seseorang yang mengidap HIV/AIDS dapat terlihat dari tes VCT maka 99,73\% menyatakan tidak namun 60,32\% 
menjawab "ya" bahwa tes HIV disebut dengat tes VCT.

\section{Tabel 2 Pengetahuan Tentang Cara Penularan HIV/AIDS per Item Pernyataan}

\begin{tabular}{|c|c|c|}
\hline Pernyataan & $\mathrm{f}$ & $(\%)$ \\
\hline \multicolumn{3}{|c|}{ Pernah Mendengar HIV/AIDS } \\
\hline Ya & 710 & 94,54 \\
\hline Tidak & 41 & 5,46 \\
\hline Tidak tahu & 0 & 0 \\
\hline \multicolumn{3}{|c|}{$\begin{array}{l}\text { Risiko penularan HIV/AIDS dapat dikurangi dengan menggunakan kondom } \\
\text { ketika berhubungan seks }\end{array}$} \\
\hline Ya & 559 & 74,43 \\
\hline Tidak & 121 & 16,11 \\
\hline Tidak tahu & 71 & 9,45 \\
\hline \multicolumn{3}{|c|}{$\begin{array}{l}\text { Risiko penularan HIV/AIDS dapat dikurangi dengan tidak berganti-ganti } \\
\text { pasangan }\end{array}$} \\
\hline Ya & 661 & 88,02 \\
\hline Tidak & 63 & 8,39 \\
\hline Tidak tahu & 27 & 3,60 \\
\hline \multicolumn{3}{|c|}{ HIV dapat menular dari gigitan nyamuk } \\
\hline Ya & 246 & 32,76 \\
\hline Tidak & 404 & 53,79 \\
\hline Tidak tahu & 101 & 13,45 \\
\hline \multicolumn{3}{|c|}{ HIV dapat menular melalui makanan } \\
\hline Ya & 274 & 36,62 \\
\hline Tidak & 416 & 55,39 \\
\hline Tidak tahu & 60 & 7,99 \\
\hline \multicolumn{3}{|c|}{ HIV dapat menular saat kehamilan } \\
\hline Ya & 657 & 87,48 \\
\hline Tidak & 68 & 9,05 \\
\hline Tidak tahu & 26 & 3,4 \\
\hline \multicolumn{3}{|c|}{ HIV dapat menular saat melahirkan } \\
\hline Ya & 627 & 83,49 \\
\hline Tidak & 79 & 10,52 \\
\hline Tidak tahu & 45 & 5,99 \\
\hline \multicolumn{3}{|c|}{ HIV dapat menular saat menyusui } \\
\hline Ya & 673 & 89,61 \\
\hline Tidak & 50 & 6,66 \\
\hline Tidak tahu & 28 & 3,73 \\
\hline \multicolumn{3}{|c|}{ HIV dapat menular melalui cara gaib } \\
\hline Ya & 28 & 3,78 \\
\hline Tidak & 662 & 88,15 \\
\hline Tidak tahu & 61 & 8,12 \\
\hline \multicolumn{3}{|c|}{ HIV dapat menular melalui kontak cairan saliva } \\
\hline Ya & 619 & 82,42 \\
\hline Tidak & 111 & 14,78 \\
\hline Tidak tahu & 21 & 2,80 \\
\hline \multicolumn{3}{|c|}{ HIV dapat menular melalui jarum suntik yang tidak steril } \\
\hline Ya & 54 & 7,19 \\
\hline Tidak & 697 & 92,81 \\
\hline Tidak tahu & 0 & 0 \\
\hline
\end{tabular}


Tabel 3 Pengetahuan Tentang Diskriminasi HIV/AIDS Per Item Pertanyaan

\begin{tabular}{lcc}
\hline Pernyataan & f & $\mathbf{\%}$ \\
\hline Seseorang dapat mengidap HIV walaupun kelihatan sehat & & \\
Ya & 617 & 82,16 \\
Tidak & 86 & 11,45 \\
Tidak tahu & 48 & 6,39 \\
Seseorang mengidap HIV terlihat dari tampilan fisik & & \\
Ya & 193 & 25,70 \\
Tidak & 558 & 74,30 \\
Tidak tahu & 0 & 0 \\
Seseorang mengidap HIV terlihat dari perilaku & & \\
Ya & 0 & 0 \\
Tidak & 751 & 100 \\
Tidak tahu & 0 & 0 \\
Seseorang mengidap HIV terlihat dari hasil tes darah/VCT & & \\
Ya & 2 & 0,27 \\
Tidak & 749 & 99,73 \\
Tidak tahu & 0 & 0 \\
Tes HIV disebut juga tes VCT & & \\
Ya & 453 & 60,32 \\
Tidak & 298 & 39,68 \\
Tidak tahu & 0 & 0 \\
\hline
\end{tabular}

Berdasarkan tabel 3 dapat diketahui bahwa hanya 4,9\% responden yang memiliki tingkat pengetahuan tentang HIV/AIDS yang baik sedangkan 62,6\% memiliki tingkat pengetahuan yang cukup.

Tabel 4 Tingkat Pengetahuan Tentang HIV/AIDS

\begin{tabular}{cll}
\hline Tingkat Pengetahuan & f & (\%) \\
\hline Kurang & 244 & 32,5 \\
Cukup & 470 & 62,6 \\
Baik & 37 & 4,9 \\
\hline
\end{tabular}

Berdasarkan tabel 4 dapat diketahui bahwa berdasarkan jenis sumber informasinya, sebagian besar responden yaitu $64,6 \%$ mengetahui informasi tentang HIV/AIDS melalui tenaga kesehatan sedangkan sumber informasi yang paling sedikit yaitu melalui teman.
Tabel 5 Distribusi Frekuensi Sumber Infromasi HIV/AIDS

\begin{tabular}{lccc}
\hline Sumber Informasi & & $\mathbf{f}$ & $\mathbf{( \% )}$ \\
\hline Poster & Ya & 139 & 18,5 \\
& Tidak & 612 & 81,5 \\
Tenaga & Ya & 485 & 64,6 \\
kesehatan & & & \\
& Tidak & 266 & 35,4 \\
Tempat ibadah & Ya & 109 & 14,5 \\
& Tidak & 642 & 85,5 \\
Sekolah/guru & Ya & 61 & 8,1 \\
& Tidak & 690 & 91,9 \\
Pertemuan & Ya & 160 & 21,3 \\
& Tidak & 591 & 78,7 \\
Teman & Ya & 6 & 0,8 \\
& Tidak & 745 & 99,2 \\
Tempat kerja & Ya & 207 & 27,6 \\
& Tidak & 485 & 64,6 \\
internet & Ya & 77 & 10,3 \\
& Tidak & 674 & 89,7 \\
lainnya & Ya & 340 & 45,3 \\
& Tidak & 411 & 54,7 \\
& & &
\end{tabular}


Berdasarkan tabel 5 tentang sikap diskriminasi pada penderita HIV/AIDS dapat diketahui bahwa sebagian besar responden akan merasa malu jika ada anggota keluarganya yang menderita HIV yaitu sebesar $44,6 \%$. Selain itu lebih dari $80 \%$ responden menyatakan setuju bahwa orang lain akan berbicara buruk jika ada yang mengidap HIV

Tabel 6 Sikap Diskriminasi Pada Penderita HIV/AIDS

\begin{tabular}{lcc}
\hline Sikap Diskriminasi & f & (\%) \\
\hline \multicolumn{2}{l}{$\begin{array}{l}\text { Akan merasa malu jika ada anggota } \\
\text { keluarga yang menderita HIV }\end{array}$} & \\
Ya & 335 & 44,6 \\
Tidak & 394 & 52,5 \\
Tidak tahu & 22 & 2,9 \\
Akan merahasiakan jika ada & anggota \\
keluarga yang menderita HIV & & \\
Ya & 306 & 40,7 \\
Tidak & 400 & 53,3 \\
Tidak tahu & 45 & 6 \\
Orang lain akan berbicara buruk jika ada \\
yang mengidap HIV \\
$\begin{array}{l}\text { Ya } \\
\text { Tidak }\end{array}$ & 607 & 80,8 \\
Tidak tahu & 111 & 14,8 \\
\hline
\end{tabular}

\section{DISKUSI}

\section{Gambaran Pengetahuan HIV/AIDS}

$$
\text { Pengetahuan adalah hasil }
$$
penginderaan manusia, atau hasil tahu seseorang terhadap objek melalui indera yang dimilikinya. Pada waktu penginderaan sampai menghasilkan pengetahuan tersebut sangat dipengaruhi oleh intensitas perhatian dan persepsi terhadap objek. Pengetahuan merupakan salah satu domain perilaku yang artinya seseorang melakukan tindakan dapat dipengaruhi oleh pengetahuan yang dimilikinya (Notoatmodjo, 2010). Pengetahuan tentang HIV/AIDS terutama tentang penularannya akan membentuk sikap seseorang tentang pencegahan penyakit ini dan akan mempengaruhi perilaku pencegahannya. Berdasarkan hasil analisis deskriptif dapat diketahui bahwa lebih dari 50\% responden memiliki pengetahuan cukup tentang HIV/AIDS dan hanya $4,9 \%$ responden memiliki pengetahuan yang baik. Hal ini menunjukan bahwa dikalangan masyarakat umum masih banyak masyarakat yang memiliki pengetahuan kurang tentang HIV/AIDS. Hasil penelitian ini sejalan dengan penelitian yang dilakukan oleh I G Wiswasa Abhinaja (2013) dimana dari 87 ibu rumah tangga yang di survei di daerah Sanur Denpasar Timur, didapatkan bahwa 54\% responden memiliki pengetahuan sedang dan $24,3 \%$ memiliki pengetahuan rendah.

Banyaknya responden dengan tingkat pengetahuan kategori cukup dapat diakibatkan oleh tinggat pendidikan responden yang masih didominasi oleh tingkat pendidikan SMP yaitu 57\%. Menurut teori yang diungkapkan oleh Notoatmodjo (2010) pengetahuan dipengaruhi oleh beberapa faktor yaitu pendidikan, informasi/ media massa, sosial budaya dan ekonomi, lingkungan, pengalaman dan usia. Salah satu faktor yang mempengaruhi pengetahuan adalah pendidikan. Pendidikan mempengaruhi proses belajar, makin tinggi tingkat pendidikan seseorang makin mudah orang tersebut untuk menerima informasi. 
Dengan pendidikan tinggi maka seseorang akan cenderung mendapatkan informasi, baik dari orang lain maupun dari media massa. Semakin banyak informasi yang masuk semakin banyak pengetahuan yang didapat (Notoatmodjo, 2010). Masih rendahnya responden dengan pengetahuan baik terlihat dari adanya pernyataan dengan jawaban yang menyimpang. Hal ini diketahui dari sebagian besar responden menjawab bahwa penularan HIV bisa melalui cairan saliva dan tidak bisa menular melalui penggunaan jarum suntik yang tidak steril. Berdasarkan Kementerian Kesehatan (2018)menjelaskan bahwa HIV hidup pada darah, cairan vagina, cairan semen pada sperma, dan air susu ibu sehingga HIV tidak dapat menular melalui bersalaman, berpelukan, berciuman, berenang, makan bersama ataupun gigitan nyamuk.

Hal yang paling banyak mendapatkan respon keliru dari responden adalah mengenai tes VCT. Lebih dari 90\% masyarakat menjawab bahwa tes darah/VCT tidak bisa untuk mengetahui apakah seseorang menderita HIV atau tidak. Walaupun masyarakat telah mengetahui bahwa tes VCT adalah tes untuk pemeriksaan HIV namun masyarakat tidak tahu lebih dalam bagaimana proses VCT dilakukan. Kekeliruan ini dapat diakibatkan oleh pengetahuan masyarakat yang rendah tentang pemeriksaan HIV. Hal tersebut didukung oleh penelitian yang dilakukan pada ibu hamil di Puskesmas II Melaya Kabupaten Jembrana Bali, yang mendapatkan hasil bahwa $75 \%$ ibu hamil tidak melakukan tes VCT. Rendahnya minat ibu hamil untuk melakukan tes VCT diakibatkan oleh kurang meluasnya informasi di masyarakat mengenai manfaat pemeriksaan VCT (Anggarini, 2013). Selain itu pada penelitian Situmeanga, Syarifb, \& Mahkotab (2017) juga menunjukan bahwa hanya 9,3\% responden yang tahu bahwa tes darah adalah cara mengetahui seseorang terinfeksi HIV/AIDS.

\section{Gambaran Sumber Informasi HIV/AIDS}

Sumber informasi adalah salah satu yang mempengaruhi pengetahuan seseorang. Semakin sering seseorang terpapar informasi maka semakin baik pengetahuan orang tersebut. Sumber informasi bisa didapatkan melalui media cetak, media elektronik maupun tatap muka langsung. Berdasarkan penelitian ini dapat ditemukan bahwa sebagian besar responden yaitu $64,6 \%$ menyatakan mendapatkan sumber informasi HIV/AIDS dari tenaga kesehatan. Hasil ini menunjukan bahwa keaktifan dari fasilitas kesehatan untuk memberikan informasi terkait dengan HIV/AIDS memiliki peranan yang besar untuk meningkatkan pengetahuan masyarakat. Hal ini dikarenakan sikap positif masyarakat kepada petugas kesehatan sebagai pemberi informasi akan menimbulkan kepercayaan masyarakat akan informasi yang diberikan.

Hasil penelitian ini sejalan dengan penelitian Cahyaningsih \& Wulandari (2013) tentang gambaran pengetahuan dan sikap ibu rumah tangga tentang 
HIV/AIDS di daerah Kabupaten Grobogan, yang menyatakan bahwa sikap positif ibu rumah tangga terhadap informasi HIV/AIDS disebabkan oleh faktor pengaruh orang lain yang dianggap penting misalnya seperti tokoh masyarakat yaitu kepala desa, RW, RT dan tenaga kesehatan seperti bidan desa. Bidan dan Kepala Desa adalah seorang panutan dalam menentukan sikap, memberi pengaruh yang besar terhadap sikap ibu rumah tangga terhadap penderita HIV/ AIDS. Walaupun pendidikan ibu rumah tangga di Desa $X$ tersebut sebagian besar tamat SMP tetapi pengetahuan mereka tentang HIV/ AIDS cukup. Hal ini dikarenakan mereka sering mendapatkan pengetahuan tentang HIV/ AIDS dari penyuluhan yang diberikan oleh bidan desa tentang HIV/ AIDS. Dengan penyuluhan tersebut maka ibu rumah tangga dapat memperoleh pengetahuan dengan rata-rata cukup.

Sumber informasi lain yang banyak didapatkan oleh masyarakat mengenai HIV/AIDS adalah melalui tempat kerja dan pertemuan. Lebih dari $20 \%$ responden menjawab pernah mendapatkan sumber informasi dari tempat kerja dan pertemuan. Hal ini dapat terjadi karena saat ini pemilik tempat usaha sudah mulai menyadari bahwa sosialisasi ditempat kerja mengenai HIV/AIDS sangat penting bagi pekerja. Sosialisasi ditempat kerja biasanya mengundang tenaga kesehatan terampil yang mampu memberikan informasi HIV/AIDS kepada pekerja. Hal ini sesuai dengan penelitian Andarmoyo (2012) yang meneliti tentang pengetahuan para buruh tentang HIV/AIDS di
Kabupaten Ponorogo mendapatkan hasil bahwa pemberian informasi dari petugas kesehatan melalui penyuluhan atau pendidikan kesehatan juga sangat signifikan dalam meningkatkan pengetahuan seseorang. Informasi tentang tentang penyakit HIV, AIDS dan penyakit menular seksual yang lainnya yang diperoleh langsung dari petugas penyuluh akan lebih mudah dimengerti, karena responden dapat bertatap muka dan bertanya langsung apabila ada hal yang kurang dipahami.

3. Gambaran Sikap Diskriminasi tentang HIV/AIDS

Pada penelitian ini didapatkan bahwa lebih dari $80 \%$ responden menyatakan setuju bahwa orang lain akan berbicara buruk jika ada yang mengidap HIV. Hal ini menunjukan bahwa saat ini masyarakat masih melakukan tindakan diskriminasi kepada penderita HIV/AIDS. Sikap diskriminasi ini dapat terjadi akibat pengetahuan responden yang lebih banyak dalam kategori cukup dan kurang. Hal ini diperkuat dengan penelitian yang dilakukan oleh Situmeanga, Syarifb, \& Mahkotab, (2017) yang mendapatkan hasl bahwa kelompok responden yang memiliki pengetahuan yang kurang tentang HIV/AIDS 1,2 kali lebih berisiko mempunyai stigma terhadap ODHA dibandingkan dengan kelompok responden yang memiliki pengetahuan yang cukup. Pengetahuan tentang HIV/AIDS dengan stigma terhadap ODHA berhubungan bermakna secara statistik. Selain itu lebih dari 50\% esponden juga menyatakan malu jika memiliki keluarga yang mengidap 
HIV/AIDS. Adanya perasaan malu pada diri seseorang jika mempunyai keluarga dengan HIV adalah munculnya stigma buruk dari masyarakat sekitar bahwa keluarga dari penderita HIV adalah keluarga yang "nakal".

\section{SIMPULAN}

Berdasarkan tingkat pengetahuan responden tentang HIV/AIDS dapat diketahui $32,5 \%$ memiliki tingkat pengetahuan kurang; 62,5\% memiliki tingkat pengetahuan cukup; dan hanya 4,9\% memiliki tingkat pengetahuan baik. Informasi tentang HIV/AIDS yang paling banyak didapatkan masyarakat berasal dari tenaga kesehatan sebesar 64,6\%. Selain itu, sebagian besar responden akan merasa malu jika ada anggota keluarganya yang menderita HIV yaitu sebesar 44,6\% dan lebih dari 80\% responden menyatakan setuju bahwa orang lain akan berbicara buruk jika ada yang mengidap HIV.

\section{SARAN}

BKKBN Provinsi Bali agar dapat memfasilitasi pelaksanaan penyuluhan HIV/AIDS yang tidak terbatas pada populasi kunci namun juga menjangkau seluruh lapisan masyarakat. Kemudian BKKBN Provinsi Bali agar dapat menjalin kerjasama dengan perangkat desa untuk melakukan sosialisasi tentang penyakit HIV/AIDS dan pencegahan diskriminasi penderita HIV kepada masyarakat.

\section{DAFTAR PUSTAKA}

Andarmoyo, S. (2012) "Hubungan Pengetahuan Dengan Sikap Calon Buruh Migran/Tki Dalam Mencegah
Hiv/Aids, Pms Dan Masalah Seksual Lainnya (Studi di Kabupaten Ponorogo)," Jurnal Florence, V(2), hal. 97-106.

Anggarini, I. G. A. A. (2013) "FaktorFaktor Yang Mempengaruhi Perilaku Pemeriksaan VCT Pada Ibu Hamil Di Wilayah Kerja Puskesmas Ii Melaya Kabupaten Jembrana Provinsi Bali," Program Studi Diploma IV Kebidanan STIKES Ngudi Waluyo Ungaran, hal. 110.

Cahyaningsih dan Wulandari (2013) "Gambaran Pengetahuan Ibu Rumah Tangga Tentang Hiv/ Aids Dan Sikap Ibu Rumah Tangga Terhadap Penderita Hiv/ Aids Di Desa X Kecamatan Toroh Kabupaten Grobogan," Ilmu dan Tek.Kesehatan, 4(1), hal. 61-69.

Direktorat Bina Farmasi Klinik dan Komunitas Ditjen Bina Kefarmasian dan Alat Kesehatan (2006) Pedoman Pelayanan Kefarmasian untuk ODHA. Jakarta: Kemenkes RI.

Djoerban, Z. (2014) Buku Ajar Ilmu Penyakit Dalam. V. Jakarta: Interna Publishing EGC.

I G Wiswasa Abhinaja, P. A. S. A. (2013) "Pengetahuan, Sikap Ibu Rumah Tangga Mengenai Infeksi Menular Seksual Termasuk HIV/AIDS Serta Perilaku Pencegahannya Di Kelurahan Sanur, Kecamatan Denpasar Selatan, Kota Denpasar Tahun 2013," Community Health, I(3), hal. 218-228.

Kemenkes RI (2013) "Pedoman Nasional Tes dan Konseling HIV dan AIDS." Jakarta: Kementerian Kesehatan RI.

Kesehatan, K. (2018) Situasi Umum HIVIAIDS dan Tes HIV Pusat Data dan Informasi Kementerian Kesehatan. Jakarta. 
Notoatmodjo, S. (2010) Promosi Kesehatan Teori dan Aplikasi. Jakarta: PT. Rineka Cipta.

Pusat Datan dan Informasi Kemenes RI (2018) "Infodatin:Situasi Umum HIV/AIDS dan Tes HIV." Jakarta: Kementerian Kesehatan RI, hal. 12.

Situmeanga, B., Syarifb, S. dan Mahkotab, R. (2017) "Hubungan Pengetahuan HIV / AIDS dengan Stigma terhadap Orang dengan HIV / AIDS di Kalangan Remaja 15-19 Tahun di Indonesia ( Analisis Data SDKI Tahun 2012 ) Relationship HIV / AIDS Knowledge related Stigma towards People Living with HIV / AIDS among Adole," Epidemiologi Kesehatan Indonesia, 1(2), hal. 35-43. 